\title{
A POTENTIAL DUAL APICAL PATHWAY IN POLARIZED REGENERATIVE CELLS OF THE MIDGUT OF MANDUCA SEXTA*
}

\author{
NoÉmi H. Borhegyi, ${ }^{* *}$ Kinga MolnÁR, Gy. Csikós and M. SASS \\ Department of General Zoology, Eötvös Loránd University, P.O. Box 330, H-1445 Budapest, Hungary
}

(Received: January 10, 2001; accepted: March 2, 2001)

\begin{abstract}
Two novel proteins with apparent molecular weight of 38 (Manduca sexta midgut MsM38) and 46kDa (MsM46) were isolated from midgut homogenates in wandering stage Manduca sexta larvae and both of them were found to be present exclusively in this tissue on Western blots. Immunocytochemical studies revealed that both proteins are expressed in the regenerative cells however, their distribution pattern is clearly different. MsM38 is localized in the cytoplasm of resting regenerative cells during the feeding period, and is accumulated in the calcospherits at the beginning of the wandering period. Along with the delamination of the larval epithelium, this protein is released apically from these vesicles. The antiserum labels an additional $76 \mathrm{kDa}$ protein in the wandering larval midgut homogenates. The appearance of this $76 \mathrm{kDa}$ protein coincides with the accumulation of the immunopositive material in the calcospherits. MsM46 is similarly distributed during the feeding period in the cytoplasm of regenerative cells. At the beginning of the wandering period it accumulates around the newly forming large apical vacuoles, that are released at the time of complete delamination of the larval epithelium. In parallel with this process MsM46, and another $40 \mathrm{kDa}$ protein, that becomes labeled from this period on Western blots appeares on the apical microvillar projections. Thus both isolated proteins are directed apically from different compartments, that raises the possibility of a dual apical routing pathway in regenerative cells.
\end{abstract}

Keywords: Dual - apical - sorting - regenerative cells - midgut

\section{INTRODUCTION}

Midgut of the tobacco hornworm (Manduca sexta, Lepidoptera, Sphingidae) is a pseudostratified epithelium supported by a framework of striated muscle and tracheoles [1]. The epithelium consists of goblet and columnar cells, and scattered regenerative cells [7]. Regenerative cells are small infrequent and can only be distinguished with difficulty from tangential sections of goblet cells. Generally they can be identified by their basal portion, wedge shaped, small nucleus, and the occasional presence of mineral inclusions called "calcospherites", that contain calcium and magnesium phosphate in large concentration, and are scattered throughout the cyto-

\footnotetext{
*Dedicated to Professor János Kovács on the occasion of his 70th birthday.

**Corresponding author; e-mail: noi@cerberus.elte.hu
} 
plasm [18]. Regenerative cells are thought to provide cells to the epithelium during growth and during replacement of the epithelium at metamorphosis [4].

During the wandering period, preparatory to the pupal moult, the regenerative cells proliferate and begin to accumulate large numbers of calcospherites throughout their cytoplasm [19]. Large vacuoles with irregular microvilli protruding into the vacuole's lumen appear very close to the apical portion of the cells. At the middle of the wandering period (day 8th) the cells form a continuous layer that can be considered as the presumptive pupal epithelium underlying the larval midgut epithelium, which by now shows signs of degeneration. Two days prior to ecdysis the larval midgut epithelium is completely sloughed off, and the content of the apical vacuoles are released from the regenerative cells. In the pupal stage the midgut is formed by columnar epithelial cells with well-developed microvillar border and is filled with calcospherites. The apical vacuoles do not reform again [16]. Until now only lysozyme was confirmed to be present in these apical vacuoles. This protein is considered to have antibacterial actions [16].

In the present study we report two novel proteins with apparent molecular mass of 38 and $46 \mathrm{kDa}$, that are expressed exclusively by the regenerative cells of feeding larvae, and during the gut restructuring (metamorphosis) both of them are released apically. On the basis of light- and electron microscopical immunocytochemical data we propose that although these two proteins are targeted to the apical secretory pathway, they are transported through different subcellular compartments, i.e. two distinct apical routing pathways of proteins may be exist in the these cells: one through the apical vacuole, and one through the calcospherites.

\section{MATERIALS AND METHODS}

Experimental animals. Tobacco hornworm (Manduca sexta) eggs were kindly provided by Prof. S. E. Reynolds (Univ. of Bath, U.K.). Larvae were reared according to his instructions based on techniques of Bell and Joachim [5] and described in Borhegyi et al. [6] in details. Specific stages of development were recognized by a staging scheme adapted from Samuels et al. [17].

\section{Protein isolation, purification and antibody development}

Protein isolation was carried out as it has been described earlier in [6]. Briefly two chilled caterpillars on the 6th day of the last larval stage were dissected, the gut was detached and the peritrophic membrane and the gut content were then removed together. The midgut was homogenized in $1 \mathrm{ml}$ of a buffer containing TRIS (3.03 $\mathrm{g} / 1000 \mathrm{ml}, \mathrm{pH}=7.4$, Reanal, Budapest) and glycine (14.4 g/1000 ml, Reanal, Budapest) and enzyme inhibitors (1 mM PMSF (phenyl-metyl-sulphonyl-fluoride), $1 \mathrm{mM}$ benzamidine, $5 \mathrm{mM} \varepsilon$-aminocapronic acid and $0.02 \% \mathrm{Na}_{2} \mathrm{~S}$ ). Freshly prepared samples were boiled for $3 \mathrm{~min}$ with equal volume of SDS sample buffer [13]. Proteins were separated on a 7.5\% preparative acrylamide gel-column (Bio-Rad Prep 
Cell, Model 491). $1.5 \mathrm{ml}$ fractions that contained the separated proteins were collected. Those fractions that contained exclusively the 38 or $46 \mathrm{kDa}$ protein in electrophoretically pure form upon SDS-PAGE analysis were pooled, dialyzed, concentrated in a SpeedVac system (RC10-10, Jouan) and tested for purity again on SDSPAGE. $100 \mu \mathrm{g}$ of purified protein was dissolved in $100 \mu \mathrm{l}$ of PBS (phosphate buffered saline, $\mathrm{pH}=7.4$ ) mixed with $100 \mu$ Freund's complete adjuvant (DIFCO Laboratories, Detroit, Michigan, USA) and injected subcutaneously in C57/Black mice. Animals were boosted 3 and 4 weeks later with $100 \mu \mathrm{g}$ of protein dissolved in $100 \mu \mathrm{l}$ of PBS and emulsified with $100 \mu \mathrm{l}$ of Freund's incomplete adjuvant. After completion of immunization mice were bled and the IgG fraction was separated from the serum by ammonium sulphate precipitation.

\section{Preparation of tissue samples}

Chilled M. sexta larvae were dissected in PBS to obtain samples for electrophoresis from epidermis, cuticle, fat body lobes, salivary glands, midgut, midgut content, Malpighian tubule, tracheae and hemolymph samples were prepared on each day of the last larval stage (for further details see $[6,8]$ ). Each samples were homogenized in a glass-teflon homogenizer and the debris was removed by a short centrifugation. Freshly prepared samples were boiled for $3 \mathrm{~min}$ with equal volume of SDS sample buffer [13] and stored at $-20^{\circ} \mathrm{C}$.

\section{Western blotting}

Titer and specificity of the antiserum to the MsM38 and MsM46 proteins were confirmed by Western blotting. Tissue homogenates (prepared as above) were run on gels containing 7.5 or $10 \%$ acrylamide (SDS-PAGE) and blotted onto Hybond nitrocellulose membrane (Amersham) in a transfer buffer containing 20\% methanol using a Bio-Rad MiniBlot system ( $75 \mathrm{~V}, 120 \mathrm{~min}$.) at $4{ }^{\circ} \mathrm{C}$. Membranes were blocked with $5 \%$ non-fat dry milk powder in TBS (tris buffered saline, $\mathrm{pH} 7.4$ ) for $45 \mathrm{~min}$, washed twice with TBS containing $0.05 \%$ Tween 20 (TTBS), and incubated with the antiserum diluted $1: 1000$ in TBS containing 3\% non-fat dry milk powder overnight at $4{ }^{\circ} \mathrm{C}$. After washing three times in TBS the nitrocellulose sheet was incubated in the presence of second antibody (alkalin phosphatase conjugated anti-mouse antibody developed in rabbit, Sigma Immuno-Chemicals) at a concentration of $1: 2000$, for $1 \mathrm{~h}$ at room temperature. The blots were developed by freshly prepared NBT-BCIP (5-Bromo-4-Chloro-3-Indolyl Phosphate/Nitro Blue Tetrazolium, Sigma) as substrate.

\section{Immunohistochemistry}

Animals were fixed in Bouin's fixative and embedded in Paraplast (Dulbeco). Five $\mu \mathrm{m}$ serial sections were cut, placed on poly-L-lysine-coated slides and dried overnight at $39^{\circ} \mathrm{C}$. Immunohistochemistry has been described in detail earlier [6]. In 
summary sections were dewaxed in xylene and rehydrated in graded ethanol series, then washed in TBS, blocked with 5\% non-fat dry milk powder, incubated with either $1: 100$ preimmune serum as negative a control or in $1: 100$ MsM38 or MsM46 antiserum diluted in TBS for overnight. After TBS washes sections were incubated for $1 \mathrm{~h}$ in the presence of alkaline-phosphatase conjugated rabbit anti-mouse antibody (Sigma) diluted 1:200 in TBS, containing 3\% non-fat dry milk powder. Sections were washed and developed using NAMP-Fast-Red tablet sets (Sigma Fast, Sigma Chemical Co.). Endogene alkaline-phosphatase were blocked with $2.4 \mathrm{mg} / \mathrm{ml}$ Levamisol (Sigma) in the developing solution. Some sections were incubated in nonimmune mouse serum. These sections remained absolutely negative in each case.

\section{Immunogold labelling}

Midgut was dissected from Manduca larvae in the wandering period (day 5th, 6th and 8th of the last larval stage), fixed in $4 \%$ paraformaldehyde, $0.5 \%$ glutaraldehyde in 0.1 $\mathrm{M}$ cacodylate buffer ( $\mathrm{pH} 7.4$ ), postfixed $1 \mathrm{~h}$ in $0.5 \%$ osmium tetroxide, dehydrated and embedded in Durcupan (ACM, Fluka). (For further details see [6]). Briefly, for postembedding immunocytochemistry sections were mounted on nickel grids incubated in $5 \% \mathrm{H}_{2} \mathrm{O}_{2}$ for $5 \mathrm{~min}$, washed, blocked with $0.5 \%$ bovine serum albumin (BSA, Sigma) and 5\% non-fat dry milk powder in PBS, incubated in primary antibody (diluted in $1: 100$ in PBS containing $0.5 \%$ BSA and $3 \%$ non-fat dry milk powder) for overnight at $4{ }^{\circ} \mathrm{C}$ in a wet chamber. After washes sections were incubated in secondary anti-mouse antibody (biotinylated anti-mouse IgG, Vector) diluted in 1:100 in PBS containing $0.5 \%$ BSA and 3\% non-fat dry milk powder, washed and finally incubated in goat anti-biotin antibody conjugated with $20 \mathrm{~nm}$ gold (British BioCell, Cardiff) diluted $1: 200$ in TTBS followed by TBS and then distilled water washes. Grids were counterstained with uranyl acetate and lead citrate. Preparations were analyzed with JEOL-100CX II electron microscope at an acceleration voltage of $60 \mathrm{kV}$.

\section{RESULTS}

\section{Protein isolation, antibody production and tissue specificity}

Midgut proteins of the larvae on the 6th day of the last larval stage (2nd day of the wandering period) were electroeluted from $7.5 \%$ polyacrylamide gels in a preparative chamber. A $38 \mathrm{kDa}$ protein (MsM38) was present in electrophoretically pure form in fractions 305-313, and a $46 \mathrm{kDa}$ protein (MsM46) in fractions 400-409 (Fig. 1). Purity of the proteins were judged by silver staining on SDS-PAGE. Polyclonal antibodies developed against the MsM38 and MsM46 proteins reacted specifically with one, single band, with the corresponding molecular mass of the originally isolated antigens on Western blots of total homogenate of feeding larval midgut. However, in case of samples prepared from the wandering period an additional $76 \mathrm{kDa}$ and a $40 \mathrm{kDa}$ band appeared, respectively. 


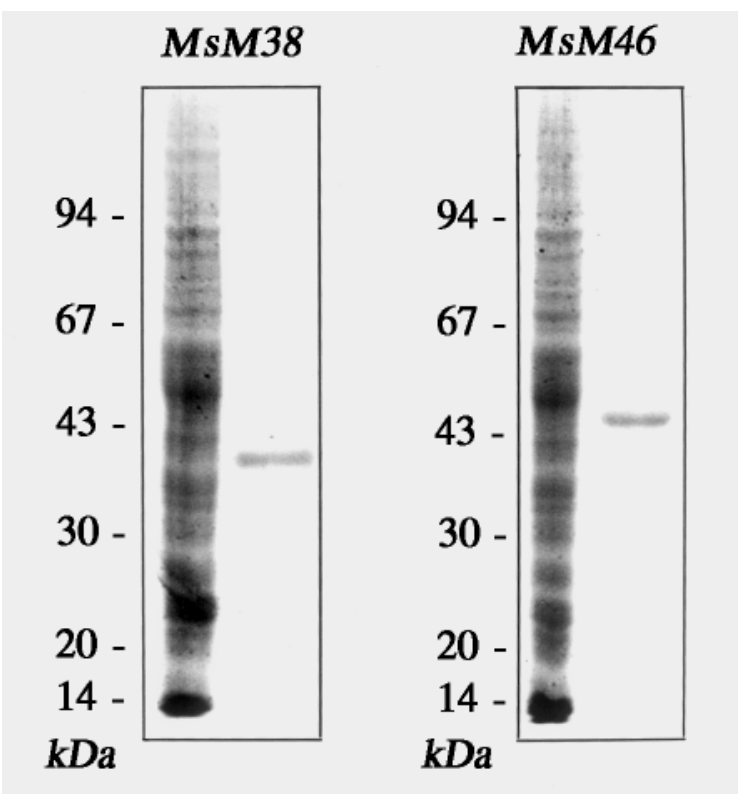

Fig. 1. SDS-PAGE of the isolated $38 \mathrm{kDa}(\mathrm{MsM} 38)$ and 46 $\mathrm{kDa}$ (MsM46) proteins, (approximately $20 \mu \mathrm{g}$ ) in parallel with the total midgut homogenate of a day 6 fifth stadium larvae from which the proteins were isolated (Coomassie Brillant Blue staining)

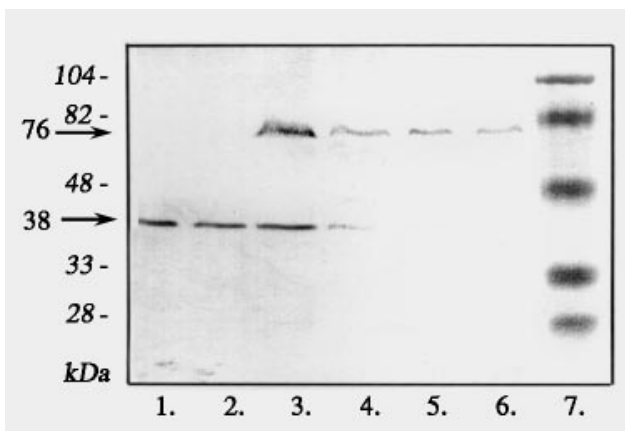

A

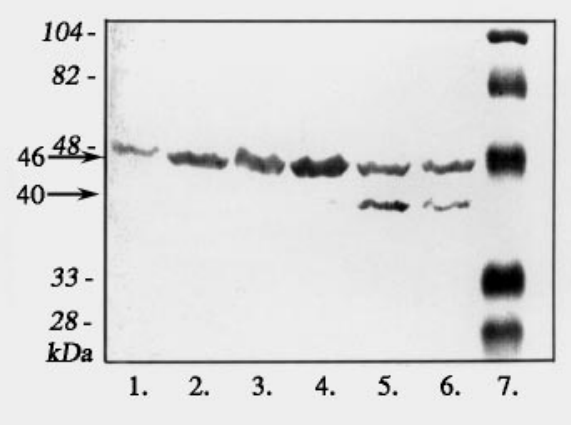

B

Fig. 2A-B. Western blotting of total midgut homogenates at different developmental stages during the fifth larval stadium probed with MsM38 (A) and MsM46 (B) antisera. A. MsM38 can be detected during the feeding (day 1 and 4, Lanes 1-2, respectively) and at the beginning of the wandering period (day 5 , Lane 3). An additional approximately $76 \mathrm{kDa}$ band appears from day 5 and is present on an almost constant level till the moulting (day 6, 7 and moulting Lanes 4-7, respectively). - B. MsM46 is present during the whole fifth stadium (Lanes same as in Fig. 2a.) while the $40 \mathrm{kDa}$ band appears exclusively at the wandering period at day 7 , and its level is sustained until the moult (Lane 9) 
To further characterize the expression pattern of the labeled proteins, whole midgut homogenates from different days of the fifth stadium were examined on Western blots. Figure 2a indicates, that the MsM38 protein was present in almost constant level during the feeding period, i.e. during the first 4 days of the last larval stage. It could be detected at the beginning of the wandering period (day 5th and 6th). From the 6th day, however, its amount decreased below the threshold in parallel with the appearance of a $76 \mathrm{kDa}$ labeled band. Its level was sustained even in the pupal midgut.

The MsM46 protein could be identified in each total homogenates independently of the period it was taken. However, in the samples prepared from late wandering larvae an additional $40 \mathrm{kDa}$ band appeared on Western blots (Fig. 2b). None of the proteins were present in the midgut fluid (in the intraperitrophic space), or in the peritrophic membrane preparations regardless of the days when the samples were taken (not indicated). Distribution of the MsM38 and MsM46 proteins showed no differences along the midgut i.e. in the anterior, medial, or posterior regions (not indicated).

Figure $3 \mathrm{a}-\mathrm{b}$ indicates that the polyclonal antisera recognized the $38 \mathrm{kDa}$ and the $46 \mathrm{kDa}$ isolated proteins in midgut homogenates, but did not bind to any other proteins of the other organs of the caterpillar. Samples taken from cuticle, epidermis, tracheae, fat body, hemolymph, salivary gland and Malpighian tubule during the fifth larval stadium were never labeled.

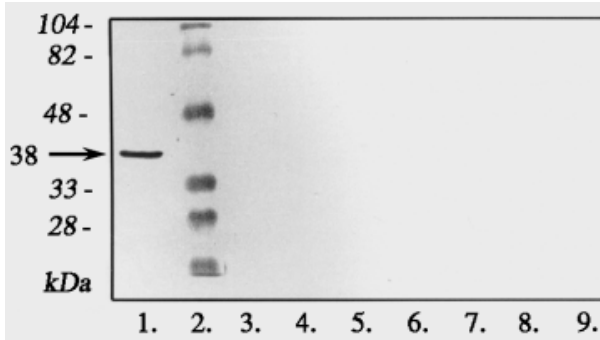

A

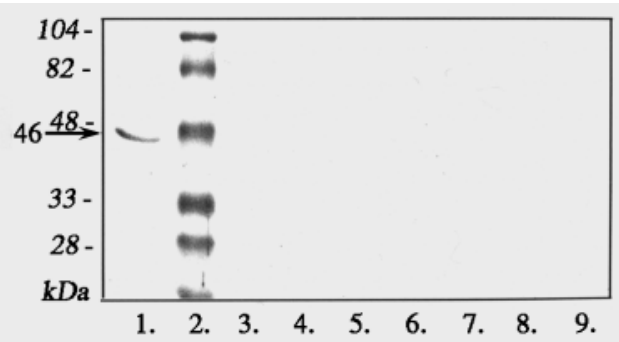

B

Fig. 3A-B. Western blotting of homogenates of different tissues of feeding fifth stadium larvae. Both the $38 \mathrm{kDa}(\mathrm{A})$ and $46 \mathrm{kDa}(\mathrm{B})$ proteins were detected only in the midgut homogenates no additional band appeared in the other homogenates. Lanes: 1. midgut 2. prestained standard 3. cuticle, 4. epidermis, 5. tracheae, 6. fat body, 7. hemolymph, 8. salivary gland, 9. Malphigian tubule

\section{Light- and electronmicroscopic immunohistochemistry}

Light microscopical immunohistochemistry carried out on cross-sections of the body of feeding and wandering fifth instar larvae (day 2nd and 6th) confirmed the results of Western blots. Positive labeling was observed only in the midgut (MsM38 Fig. 4a-f, MsM46 Fig. 5a-f), while all other organs examined remained unlabelled. The pattern of positive staining however showed clear differences using the two antisera. 


\section{$\operatorname{MsM38}$}

During the feeding period MsM38 was observed at the light microscopical level exclusively in the regenerative cells of the midgut epithelium both in the anterior and the posterior parts. The labeling was even throughout the cytoplasm of the cells. Relatively large nuclei $(\mathrm{Nu})$ localized in the middle part of the cells also remained unlabelled. Figure 4a shows the typical labeling pattern in the anterior region. From the 5th day of the last larval stage i.e. at the beginning of the wandering period a stronger and scattered positive reaction appeared in the cytoplasm of these cells, that were found to be large vesicles at the electronmicroscopical level (Fig. 4c, e-f). During this period the regenerative cells multiply and form a continuous cell layer underneath the larval midgut cells. Few large apical vacuoles appear inside each regenerative cells that can be clearly distinguished from the previously mentioned vesicles, since these vacuoles have undifferentiated microvilli in their lumen (Fig. $4 c)$. MsM38 antiserum clearly labeled only the vesicles but did not the apical vacuoles during this period (Fig. 4e-f) When the larval epithelium finally sloughed off, the regenerative cells secrete the apical vacuoles and some of the vesicles, and produce an extensive microvillar border into the midgut lumen (Fig. 4b). At this period, the MsM38 protein could be detected on the surface of the microvilli and it was still present in the calcospherites (Fig. 4d). This labeling pattern remained unchanged during the molting period and was sustained in the pupal stage as well (not indicated).

\section{MsM46}

During the feeding period, MsM46 was only faintly detectable in the midgut regenerative cells, while the other cell types, the columnar and the goblet cells remained clearly negative (not shown). At the beginning of the wandering period (day 5th and 6th) the antiserum gave a strong positive reaction around the forming large apical vacuoles, while the cytoplasm of the cells became unstained (Fig. 5a-b, e). The nuclei of the regenerative cells as well as their plasma membrane remained negative. At day 7th the larval epithelial cells began to slough off the basal lamina. As delamination of the epithelium became complete (day 8th), and the regenerative cells were not in contact any more with the columnar and goblet cells, they released the content of the apical vacuoles. This process is demonstrated in Fig. 5c-d. From this point the MsM46 protein could be detected on the newly formed brush border of the regenerative cells (Fig. 5f). Cytoplasmic structures were not labeled. This labeling pattern was sustained during the molting period and in the pupa as well (not shown). 

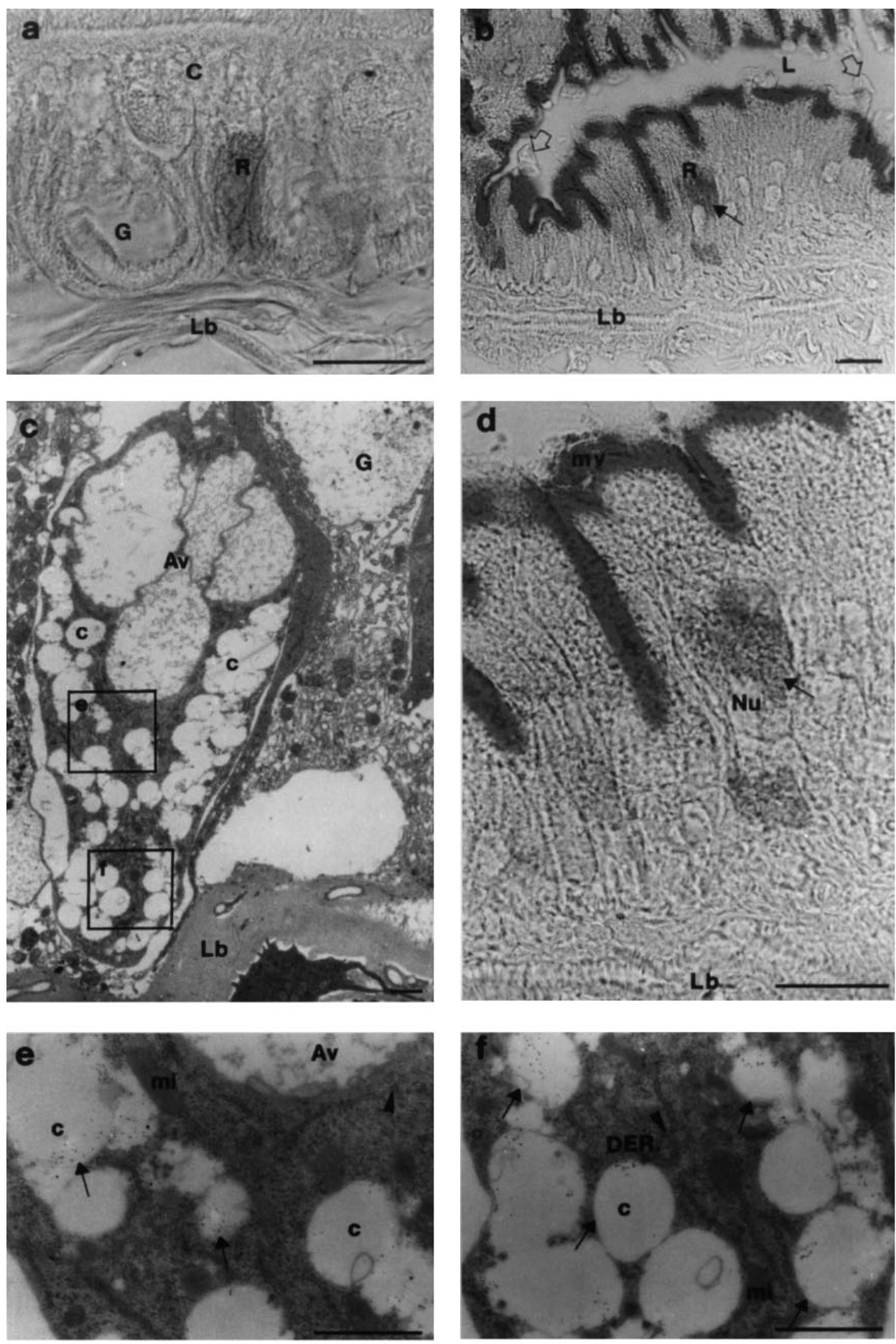

Acta Biologica Hungarica 52, 2001 


\begin{abstract}
Fig. 4a-f. Light and electron micrographs showing different labelling patterns in cross-sections from the anterior region of the midgut of feeding and wandering larvae stained with the antiserum raised against the MsM38 protein. $a$. Light micrograph showing the anterior region of the midgut of an actively feeding day 2 fifth stadium larvae. The antiserum labelled exclusively the regenerative cells (R). Columnar (C) and goblet $(\mathrm{G})$ cells and the basal lamina $(\mathrm{Lb})$ are negative. $-b$. Cross-section from the anterior region of a day 8 wandering larvae. Strong labelling is visible at the microvillar projections of the regenerative cells (R), in addition dispersed stain is seen in the cytoplasm. The basal lamina (Lb) and the released apical vacuole contents (open arrows) are negative. Boxed area is enlarged on panel $d$. $-c$. Low power electron micrograph of a differentiating regenerative cell, and of a delaminating goblet cell $(\mathrm{G})$. Apical vacuoles $(\mathrm{Av})$ prior to release can be clearly seen in the regenerative cells. Large percent of the cells cytoplasm is constituted of vesicles called calcospherits (c). Boxed areas are enlarged in panel $e-f$. $-d$. MsM38 antiserum labels the cytoplasm (arrow), and the apical microvillar border (mv). The nucleus $(\mathrm{Nu})$ and the basal lamina $(\mathrm{Lb})$ are negative. $-e-f$. High power micrographs of the cytoplasmic structures of the regenerative cell from panel $c$. Immunogold particles can be found in the lumen of the calcospherits, and in the cisternae of the endoplasmic reticulum. No labelling can be detected in the lumen of the apical vacuole. Bars: $a, b, d 25 \mu \mathrm{m}, c, e-f 1 \mu \mathrm{m}$
\end{abstract}

\title{
DISCUSSION
}

Insect midgut epithelium undergoes a basic restructuring during metamorphosis [4]. Regenerative cells that have not developed their polarized shape yet, multiply in response to the elevated level of 20-hydroxi-ecdyson, replace the larval epithelial cells and differentiate into low columnar cells. In the meantime, they accumulate large numbers of special vesicles that are called "calcospherits" after their high calcium and magnesium phosphate content. Along with the proliferation large vacuoles appear in these cells which are released prior to larval/pupal molt. Until now only one protein, lysozyme has been described to be produced and secreted apically by the regenerative cells [16].

To better understand the process in which these initially non-polarized cells acquire polarized shape, and to characterize the sorting properties of the regenerative cells, several proteins were isolated from midgut homogenates of wandering stage larvae, and polyclonal antibodies has been raised against them. After detailed examination two of them with apparent molecular mass of 38 and $46 \mathrm{kDa}$ were confirmed to be exclusively produced by the regenerative cells. Both proteins were found to be present only in the midgut upon Western blot analysis, the antisera did not recognize any additional proteins in any of the examined tissues.

MsM38 is present in the midgut homogenates from the beginning of the fifth stadium until the wandering begins. On the 5th day, however, its amount decreases, and is replaced by a $76 \mathrm{kDa}$ molecule, that is recognized by the antiserum, which might be due to alternate splicing of the mRNA, or a lack of post-translational cleavage, or a covalent dimerization. The elevated level of 20-hydroxi-ecdyson on the 4th day of the last larval stage is known to influence the gene expression pattern during the 

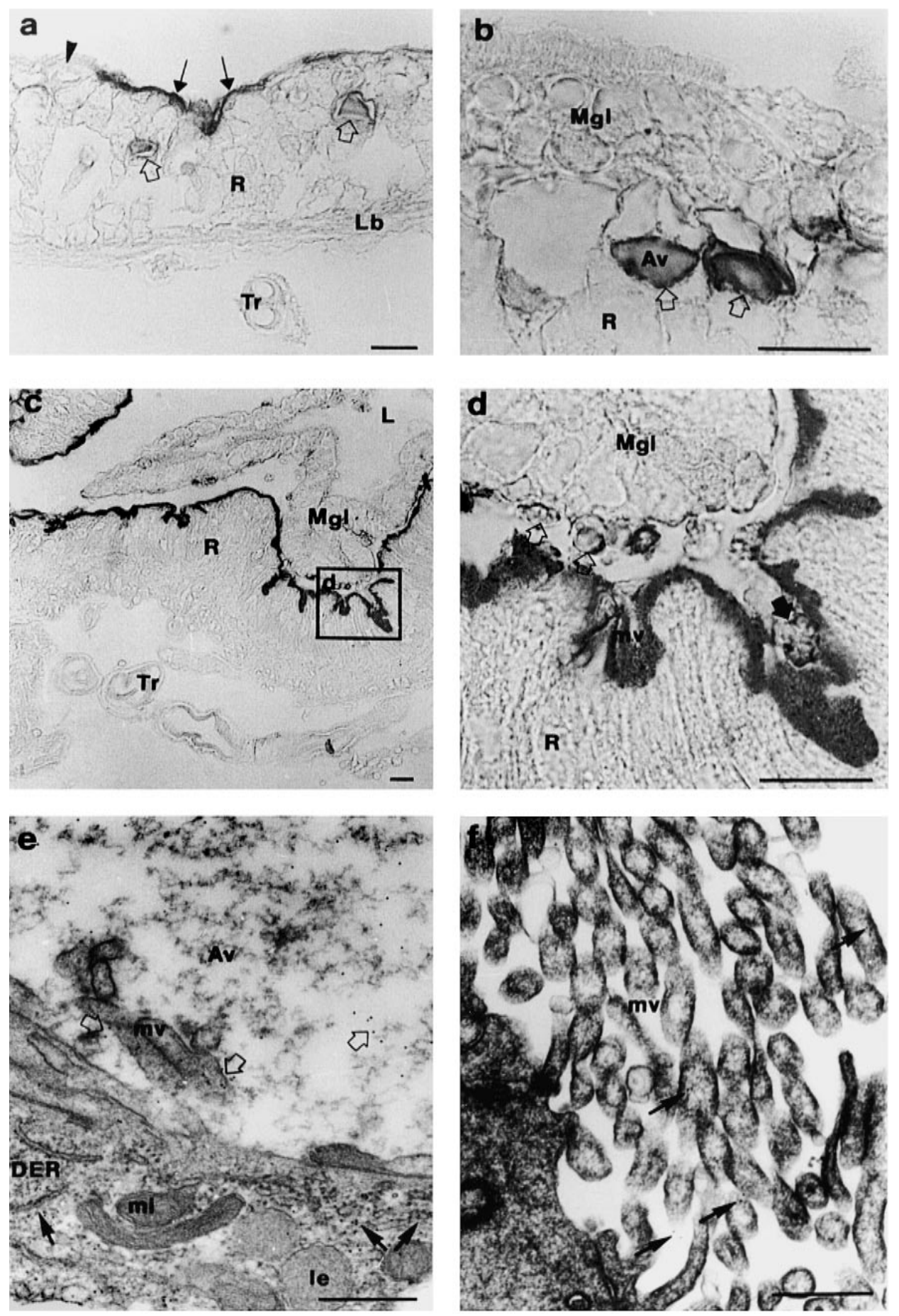

Acta Biologica Hungarica 52, 2001 
metamorphosis [10], which can also be a plausible explanation for the exchange of the $38 / 76 \mathrm{kDa}$ form on the 5 th day of the last larval stage. The $76 \mathrm{kDa}$ form persists until the larval/pupal molt. Considering the data obtained from light- and electronmicroscopical examination, the distribution pattern of the positive label changes on the 5th day in parallel with the $38 / 76 \mathrm{kDa}$ exchange on Western blot analysis.

During the feeding period i.e. on the first 4 days of the last larval stage, the MsM38 protein is exclusively present in the cytoplasm of the resting non-differentiated regenerative cells. Following the ecdyson peak on the 4th day, the regenerative cells multiply, acquire large number of calcospherites, and begin to accumulate the MsM38 protein in these vesicles, in parallel with the appearance of the large apical vacuole. Electronmicroscopical data however, support those observations that the MsM38 protein is not included into these vacuoles, it is rather present in the calcospherites, and in the cisternae of the rough endoplasmic reticulum. Prior to the ecdysis when the apical vacuoles are released (day 8th) and the cells acquire a full-polarized shape with apical microvillar brush border, the pattern of the proteins distribution changes, and it partially appears on the surface of the newly formed apical microvilli, i.e. it is secreted apically. Calcospherites are known to be released into the midgut lumen [11], and we propose, that the appearance of this proteins on the luminal surface of the midgut cells is due to secretion from these special vesicles. The lack of the protein in the midgut fluid is probably due to its trapping by the glycocalyx, that is present on the microvillar surface of the cells. This finding is supported thened by the light microscopical results that show no positive labeling in the lumen, rather on the surface of the microvilli.

MsM46 unlike MsM38 is present during the fifth stage in constant level in the midgut homogenates on Western blots. At the middle of the wandering period (day

Fig. 5a-f. MsM46 localisation with light- and electronmicroscopical immunocytochemistry. Sections are from the anterior part of the midgut from a wandering fifth stadium larvae (day 6 and 8 ). $-a-b$. In day 6 wandering larvae the antiserum labels the developing apical vacuoles (Av, open arrows) of the regenerative cells (R). In case of those regenerative cells, that already released their vacuoles, the immunopositive staining can be found on the apical brush border (arrows). The delaminating larval midgut epithelium ( $\mathrm{Mgl}$, arrowhead), the basal lamina ( $\mathrm{Lb})$ and the tracheae $(\mathrm{Tr})$ are negative. $-c$. In day 8 . wandering larvae the epithelium is built up exclusively by regenerative cells, the larval epithelium can be seen in the lumen of the midgut. Immunopositive labelling can be identified only in the apical microvillar projections of the regenerative cells, and in the apical vacuoles membrane that are in the course of releasing their content. Boxed area is enlarged in panel $d$. L: lumen of the midgut. $-d$. Apical region of a regenerative cell (R). Arrow indicates intensive labelling on the membrane of an apical vacuole just about to release its content. Apical region of a columnar $(C)$ and a goblet $(G)$ cell stained with the antiserum raised against the MsM41 protein. $c$, Negative control from the same area of a columnar cell stained with preimmune serum. $-e$. Electron micrograph demonstrates that in day 6 wandering larvae the antiserum labels the membrane of the large apical vacuole, that have primitive microvillar projections inside the vacuole lumen. Immunogold particles can be identified in the vacuole lumen as well. Further labelling can be seen above the rough endoplasmic reticulum (DER, arrows), and a scattered labelling is visible in the cytoplasm. mi: mitochondria, le: late endosome. $-f$. In day 8 wandering larvae, the midgut epithelium is built up by regenerative cells. Immunogold particles can be identified exclusively on the microvillar (mv) brush border (arrows). - Bars: $a-d .25 \mu \mathrm{m}, e-f 0.5 \mu \mathrm{m}$ 
8th), an additional, $40 \mathrm{kDa}$ band appears in parallel with the $46 \mathrm{kDa}$ band, that can be due to alternate splicing of the mRNA. From this day, similarly to the MsM38, the distribution pattern of the MsM46 changes. Previously during the feeding period it can be detected faintly in the cytoplasm of the undifferentiated regenerative cells, but at the beginning of the wandering period it accumulates in the membrane or in association with the membrane of the apical vacuoles. These vacuoles along with the delamination of the larval epithelium are released into the midgut lumen at day 8 in parallel with the appearance of the $40 \mathrm{kDa}$ band in the midgut homogenates on Western blot. As soon as the exocytosis occurs, the positive label becomes visible on the surface of the microvilli of the newly polarized regenerative cells. Some scattered staining can be seen around the released content of the vacuoles. The reason why these special vacuoles are formed and their function is still unknown. We propose that their formation is due to the lack of free membrane surface of the regenerative cells while proliferating, and its release is the consequence of the complete delamination of the larval midgut epithelium, that frees the apical membrane domain of these cells.

Single epithelial cells in suspension culture exhibit non-polarized distribution of marker proteins [20]. Extracellular contacts either with another cell or with extracellular matrix initiates the segregation of proteins into contacting and non-contacting surface domains. Cell-cell adhesion is required to restrict the localization of basolateral membrane proteins in the plasma membrane [3] while cell adhesion to extracellular matrix results in the localization of apical marker proteins in the non-contacting surface [15]. It is well established that apically targeted vesicles need non-contacting surface to be able to fuse with plasma membrane. If a potentially polarized cell lacks free membrane surface, apical vesicles not being able to fuse with the basolateral membrane domain tend to fuse with each other, and form large vacuole-like structures [9]. We propose that, in case of the regenerative cells, the elevated molting hormone level switch those genes on that initiate the acquisition of the polarized phenotype. Although as long as the larval epithelium is not completely sloughed off, the regenerative cells lack free membrane surface, thus unable to develop the apical membrane domain. Vesicles that are apically targeted fuse with each other and the result is the appearance of the large apical vacuoles. As soon as the contacting membrane surface becomes free of the larval columnar and goblet cells these vacuoles become able to fuse with the membrane, and thus the apical domain is formed in one step together with the exocytosis of these vacuoles. This process can be followed using the MsM46 antiserum, from the beginning of the formation of these vacuoles until their release into the midgut lumen, results in the appearance of the MsM46 proteins on the newly formed microvillar projections. However, the exact role of the MsM46 protein in this process is not yet fully understood.

Several proteins have already been isolated and characterized from the midgut of Lepidopteran insects, including some midgut proteins of Manduca as well. However, in the molecular weight range between $30 \mathrm{kDa}-50 \mathrm{kDa}$ only a single protein has been identified and described earlier. It is a subunit of Manduca sexta vacuolar proton pumping V-ATPase [12]. The molecular mass of one of the proteins of theV-ATPase 
complex (called as M40 protein) is $40 \mathrm{kD}$ [14]. Knowing the uncertainty of molecular mass determination by gel electrophoresis, the question arised whether one of the proteins isolated here is identical with this previously identified M40 protein? In larval midgut of the model insects V-ATPases occur in the apical plasma membrane domain of goblet cells, where they energize the alkalinization of the gut lumen up to a $\mathrm{pH}$ of more than 11 [2]. It has been reported that the antibody raised against the M40 protein recognized the area of the folded goblet cell apical membrane in the posterior region of midgut. No obvious labelling of the regenerative cells was detected [12]. We concluded that none of the isolated proteins are identical with the M40 protein, thus both of them are newly purified, and not yet described.

Considering the fact that the MsM38 protein is secreted apically through the calcospherits, while the MsM46 protein is through the apical vacuoles, raises the possibility of a bi-directional apical routing in the regenerative cells, however the sorting machinery and the signals that direct the proteins into each of these ways need further examination.

\section{ACKNOWLEDGEMENTS}

I wish to thank Ms. Károlyné Válóczi, Ms. Ildikó Szabó and Ms. Zoltánné Sarody for excellent technical assistance. This work has been supported by the Hungarian Ministry of Education under grant No. FKFP-0163/2000, provided to M.S.

\section{REFERENCES}

1. Anderson, E., Harvey, W. R. (1966) Active transport by the cecropia midgut. II. Fine structure of the midgut epithelium. J. Cell Biol. 31, 107-134.

2. Azuma, M., Harvey, W. R., Wieczorek, H. (1995) Stoichiometry of $\mathrm{K}^{+} / \mathrm{H}^{+}$antiport helps to explain extracellular pH 11 in a model epithelium. FEBS Lett. 361, 153-156.

3. Balcarova-Stander, J., Pfeiffer, S. E., Fuller, S. D., Simons, S. (1984) Development of cell surface polarity in the epithelial Madin-Darby canine kidney (MDCK) cell line. EMBO J. 3, 2687-2694.

4. Baldwin, K. M., Hakim, R. S. (1991) Growth and differentiation of the larval midgut epithelium during molting in the moth, Manduca sexta. Tissue Cell 23, 411-422.

5. Bell, R. A., Joachim, F. A. (1976) Techniques for rearing laboratory colonies of tobacco hornworms and pink bollworms. Ann. Ent. Soc. Am. 69, 365-373.

6. Borhegyi, H. N., Molnár, K., Csikós, Gy., Sass, M. (1999) Isolation and characterization of an apically sorted $41 \mathrm{kDa}$ protein from the midgut of tobacco hornworm (Manduca sexta). Cell Tissue Res. 297, 513-525.

7. Cioffi, M. (1979) The morphology and fine structure of the larval midgut of a moth (Manduca sexta) in relation to active ion transport. Tissue Cell 11, 467-479.

8. Csikós, Gy., Molnár, K., Borhegyi, H. N., Talián, Cs. G., Sass, M. (1999) Insect cuticle, an in vivo model of protein trafficking. J. Cell Sci. 112, 2113-2124.

9. Gilbert, T., Rodriguez-Boulan, E. (1991) Induction of vacuolar apical compartments in the Caco-2 intestinal epithelial cell line. J. Cell Sci. 100, 451-458.

10. Horodyski, F. M., Riddiford, L. M. (1989) Expression and hormonal control of a new larval cuticular multigene family at the onset of metamorphosis of the tobacco hornworm. Dev. Biol. 132, 292-303. 
11. Humbert, W. (1978) Cytochemistry and X-ray microprobe analysis of the midgut of Tomocerus minor Lubbock (Insecta, Collembola) with special references to the physiological significance of the minreal concretions. Cell Tissue Res. 196, 39-57.

12. Klein, U., Löffelmann, G., Wieczorek, H. (1991) The midgut as a model system for insect $\mathrm{K}^{+}$-transporting epithelia: immunocytochemical localization of a vacuolar-type $\mathrm{H}^{+}$pump. J. exp. Biol. 161, $61-75$.

13. Laemmli, U. K. (1970) Cleavage of structural proteins during the assembly of the head of bacteriophage T4. Nature 227, 680-685.

14. Merzendorfer, H., Harvey, W. R., Wieczorek, H. (1997) Sense and antisense RNA for the membrane associated $40 \mathrm{kD}$ subunit M40 of the insect V-ATPase. FEBS Letters 411, 239-244.

15. Ojakian, G. K., Nelson, W. J., Beck, K. A. (1997) Mechanism of de novo biogenesis of an apical membrane compartment in groups of simple epithelial cells surrounded by extracellular matrix. $J$. Cell Sci. 110, 2781-2794.

16. Russell, V. W., Dunn, P. E. (1991) Lysozyme in the midgut of Manduca sexta during metamorphosis. Arch. Insect Biochem. Physiol. 17, 67-80.

17. Samuels, R. I., Charnley, A. K., Reynolds, S. E. (1993) A cuticle-degrading proteinase from the moulting fluid of the tobacco hornworm, Manduca sexta. Insect Biochem. Mol. Biol. 23, 607-614.

18. Turbeck, B. O. (1974) A study of concentrically laminated concretions, "spherites" in the regenerative cells of the midgut of lepidopterous larvae. Tissue Cell 6, 987-1018.

19. Waku, Y., Sumimoto, K. I. (1974) Metamorphosis of midgut epithelial cells in the Silkworm (Bombyx mori $\mathrm{L}$.) with special regard to the clacium salts deposits in the cytoplasm. II. Electron microscopy. Tissue Cell 6, 127-136.

20. Wang, A. Z., Ojakian, G. K., Nelson, W. J. (1990) Steps in the morphogenesis of a polarized eithelium. II. Disassembly and assembly of plasma membrane domains during reversal of epithelial cell polarity in multicellular epithelial (MDCK) cysts. J. Cell Sci. 95, 153-165. 